\title{
Pericardial Effusion with Cardiac Tamponade as a Form of Presentation of Primary Hypothyroidism
}

\author{
Acir Rachid, Leiber C. Caum, Ana Paula Trentini, Carlos A. Fischer, Dênis A. J. Antonelli, \\ Rafael P. Hagemann \\ Curitiba, PR - Brazil
}

\begin{abstract}
The authors describe a case of pericardial effusion accompanied by cardiac tamponade caused by primary hypothyroidism. Diagnosis was made by exclusion, because other causes of cardiac tamponade are more frequent. Emergency treatment of cardiac tamponade is pericardiocentesis (with possible pericardial window), and, after stabilization, performance of hormonal reposition therapy with L-thyroxin.
\end{abstract}

Hypothyroidism, a disease with a multisystemic character that may present clinically in various forms, one being unusual pericardial effusion, is a cardiovascular complication that, according to the literature, is associated with hypothyroidism in $30 \%$ to $80 \%$ of cases ${ }^{1,2}$. However, the occurrence of hypothyroidism and pericardial tamponade is a rare event. Pericardial effusion has a high concentration of protein and, like other serous effusions of hypothyroidism, its pathogenesis is not fully understood ${ }^{3}$. The slow accumulation of liquid observed in the pericardial space is due to the frequent rarity of hemodynamic premonitory signs, even in the presence of large effusions. In this article, we report a the case of a patient who presented with pericardial effusion evolving rapidly to cardiac tamponade, the cause being primary hypothyroidism.

\section{Case Report}

A female patient, 47 years of age, was admitted to the service of the Medical Clinic of the Clinics Hospital of the Federal University of Paraná. She complained about shortness of breath, weakness, and edema, with dyspnea after light and heavy exertion starting 2 years earlier. The patient also reported asthenia and lower limb, facial, and abdominal

Hospital das Clínicas de Curitiba da Universidade Federal do Paraná Mailing address: Acir Rachid - Rua Saldanha da Gama, 846 - 80430-150 - Curitiba, PR - Brazil - E-mail: fischer @ medcenter.com

Received for publication on $1 / 12 / 01$

Accepted on $5 / 9 / 01$ edema, but denied the existence of any other health problem except depression (untreated for the last few months). She was previously hospitalized for dyspnea. Her symptoms had been treated but her clinical picture had never been investigated. She did not have a family history of morbidity; the patient was not a smoker or alcohol consumer, and at the time was not using any medication. Systemic examination revealed intestinal constipation and palpitation. No family history of importance (including tuberculosis) was reported.

On physical examination, she had a regular general condition, hypocoloration, and eupnea. Her arterial pressure was $120 / 90 \mathrm{mmHg}$, pulse $90 \mathrm{bpm}$, respiratory frequency $16 \mathrm{rpm}$, and she had $36.5^{\circ} \mathrm{C}$ temperature. On segmental examination, she had engorged jugulars, crepitating stertors on pulmonary bases, hypophonetic yet rhythmic cardiac murmurs, slight lower limb edema, and slowed, deep tendinous reflexes.

Complementary examinations (performed on the first 3 days of hospitalization) showed, on thoracic radiography, a marked increase in the volume of the cardiac silhouette and slow right-side pleural effusion (Figure 1), and on electrocardiography, sinus rhythm, low voltage on the frontal plane, and diffuse alteration of ventricle repolarization. The laboratory examination hemogram showed the following: hematocrit, 39.5\%; hemoglobin, $13.2 \mathrm{~g} / \mathrm{dL}$; mean corpuscle volume, $100 \mathrm{fL}$; leukocytes, 6,100 (5\% rods); platelets, $311,000 /$ uL; urea, $39.6 \mathrm{mg} / \mathrm{dL}$; creatinine, $0.78 \mathrm{mg} / \mathrm{dL}$; serum glucose, $78.5 \mathrm{mg} / \mathrm{dL}$; protrombin time, 13s; AST 81 units/L; LDH, 791 units/L; CK, 1,438 units/L; VHS, 17s in 1h; nonreactive FAN; rheumatoid factor $<20$ (normal, nonreactive); VDRL, nonreactive. The partial urine was normal.

Echography showed bilateral pleural effusion, voluminous pericardial effusion, and the remaining structures were normal. An echocardiography investigation revealed a large circumference effusion. The heart showed intense mobility, preventing the obtainment of ventricle measurements. However, subjective analysis revealed normal dimensions and heart chamber functions.

On the $5^{\text {th }}$ day of hospitalization, the patient had classical signs of cardiac tamponade (increased jugular disten- 


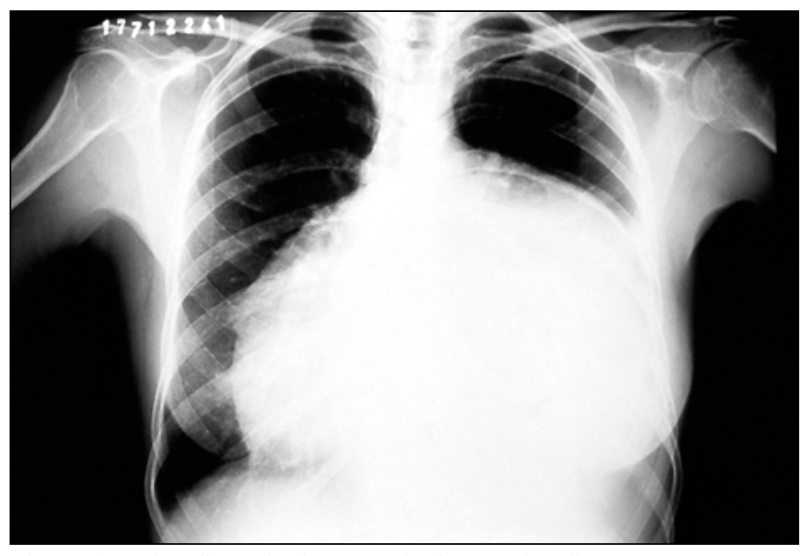

Fig. 1 - Thoracic radiography demonstrating increased cardiac area.

sion, muffling of cardiac murmur, and paradoxical pulse); a renewed urgent echocardiography showed voluminous pericardial effusion, associated with signs of cardiac tamponade. Upon the performance of pericardiocentesis, an outpouring during 30 minutes of approximately $500 \mathrm{~mL}$ of citrine-yellow fluid, from a total calculated at $1,500 \mathrm{~mL}$, was observed. Laboratory analysis of pericardial fluid revealed: 50 leukocytes/uL, 8 neutrophils/uL, 14 lymphocytes/uL, 4 mesothelial cells/uL, 11 macrophages/uL, $8 \mathrm{~g} / \mathrm{dL}$ protein, 38mg/ dL glucose, amylase 116, pH 5.5,390units/L LDH. Grambacterioscopy did not reveal the presence of bacteria. Staining by Ziehl-Nielsen did not visualize BAAR. Culture for aerobic and anaerobic bacteria was negative. Direct mycological and culture for fungi were negative. Search for LE cells and oncotic cytology were negative.

Search for LE cells in the blood was negative. PPD was nonreactive. Radiography of the hand and pulses was normal. TSH was 70.14um/L (normal values are between 0.49 $4.67 \mathrm{um} / \mathrm{L}$ ), and free T4 was undetectable, thus diagnosing hypothyroidism. Renewed echocardiography, 12 days after pericardiocentesis, showed a large volume of pericardial effusion. The left ventricle showed decreased relaxation, normal internal dimensions and systolic function, and minimal mitral reflux.

We decided to perform a pericardiotomy and pericardial window (with a biopsy). Anatomopathological analysis showed negative results for granulomatous or other types of diseases. The patient evolved favorably during the postoperative period, without complaints, although thoracic radiography demonstrated pneumomediastinum and obliteration of the left costophrenic sinus. Treatment was with levothyroxine at $75 \mathrm{mcg} /$ day and after 3 days, $125 \mathrm{mcg} /$ day. She was discharged from the hospital and was followed up as an outpatient.

\section{Discussion}

The first known description of pericardial effusion in a hypothyroid patient dates back to $1918^{4}$. Since then, several publications have reported on the association between hypothyroidism and pericardial effusion, and even other serous effusions ${ }^{5}$. Pericardial effusion is considered the most frequent cardiovascular complication of hypothyroidism, with a prevalence estimated to be between $30 \%$ and $80 \%{ }^{1,2}$. However, Kabadi and Kumar ${ }^{6}$ have questioned this index, associating only cases of severe hypothyroidism with such a high prevalence. The causes related to this accumulation of fluid in the serosa in hypothyroidism remain controversial; some authors believe its cause to be an accumulation of hygroscopic mucopolysaccharides. Parving et $\mathrm{al}^{3}$ demonstrated as causes; a combination of extravasation of albumin and decreased lymph flow.

Cardiac tamponade as a complication of hypothyroidism is very rare; Jiménez-Nácher et al ${ }^{7}$ cite that until 1992 less than 30 cases had been described in the world literature. This low incidence is probably due to the slow accumulation of liquid and to cardiac distensibility ${ }^{8}$. Factors described as provoking cardiac tamponade include infection, spontaneous pericardial hemorrhage, thyroid therapy, and abdominal paracentesis.

Identification of cardiac tamponade in hypothyroidism is therefore difficult and commonly mistaken for cardiac failure due to its symptoms of tachycardia, rise in venous pressure, lower limb edema, and increased cardiac silhouette on radiography.

In our case, diagnosis was based on clinical and echographic findings. Hypothyroidism as the cause of the pericardial effusion and tamponade was diagnosed by an exclusion criterion, because other afflictions (neoplasm, tuberculosis) are the most frequent causes of nontraumatic pericardial effusion. The etiological search of cardiac tamponade should always be performed, even in patients with evident primary hypothyroidism, because this association is a rare one, and other causes of cardiac tamponade require a different or more aggressive treatment ${ }^{9}$.

Controversy exists regarding the form of drainage of cardiac tamponade. Some authors suggest an immediate surgical approach (pericardial window) to prevent recurrence; others prefer pericardiocentesis and in case of recurrence, an option for the window ${ }^{10}$. Advantages of the pericardial window are possible tissue biopsy of the pericardium and prevention of recurrences.

Treatment of hypothyroidism is always mandatory following tamponade drainage, because, generally, a residue of the effusate following pericardiocentesis (with a high potential for recurrence) disappears following appropriate therapy over a period varying between 1 month and 1 year, ranging up to 15 months. The most recommended therapeutic scheme is L-thyroxin, at an initial low dose $(25 \mathrm{mcg} /$ day $)$, increased only progressively, because high doses may propitiate new effusions or decompensation towards tamponade. In the present case, the dose used was of $75 \mathrm{mcg} /$ day, increased to $125 \mathrm{mcg} /$ day within 3 days, with indefinite continuation. 


\section{References}

1. Hardisty CA, Naik DR, Munro DS. Pericardial effusion in hypothyroidism. Clin Endocrinol 1980; 13: 349-54.

2. Kerber RE, Sheman B. Echocardiographic evaluation of pericardial effusion in myxedema. Incidence and biochemical and clinical correlations. Circulation $1975 ; 52: 823-7$.

3. Parving HH, Hansen JM, Nielson SL, Rossing N, Munck O, Lassen NA. Mechanisms of edema formation in myxedema: incresead protein extravasation and relatively slow lymphatic drainage. N Engl J Med 1979; 301: 460-5.

4. Zondek H. Das myxodemherz. Munc Med Wochenschr 1918; 65: 1180-3.

5. Gottehrer A, Stanford G, Sahn AS, Roa J, Chernow B. Hypothyroidism and pleural effusions. Chest 1990; 98: 1130-2.
6. Kabadi UM, Kumar SP. Pericardial effusion in primary hypothyroidism. Am Heart J 1990; 120: 1393-5.

7. Jiménez-Nácher JJ, de Alonso N, Veja B, et al. Taponamiento cardíaco como forma de presentación de un hipotiroidismo primario en una mujer joven. Rev Clin Esp 1993; 193: 290-2.

8. SmolarEN, Rubin JE, Avramides A, etal. Cardiac tamponate in primary myxedema and review of literature. Am J Med Sci 1976; 272:345-52.

9. Sainz AJ, Encinar JC, Torregrosa IQ, Parreño LT. Tamponamiento pericárdico como forma inicial de presentación de hipotiroidismo primario. Ver Esp Cardiol 2000; 53: 145-6.

10. Auguet T, Vázquez, Nolla J, Solsona JF. Cardiac tamponade and hypothyroidism. Int Care Med 1993; 19: 241.

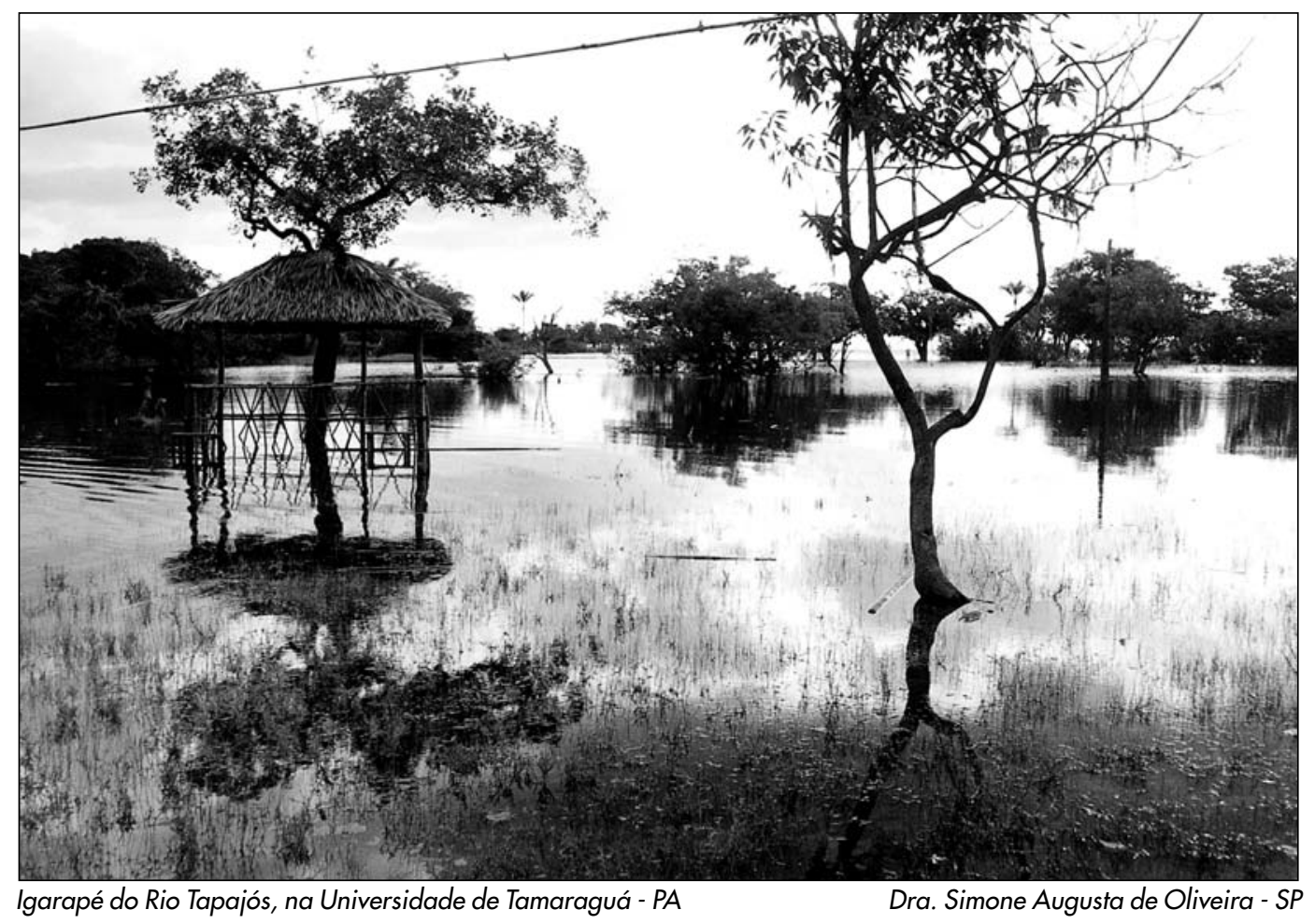

Editor da Seção de Fotografias Artísticas: Cícero Piva de Albuquerque

Correspondência: InCor - Av. Dr. Enéas C. Aguiar, 44 - 05403-000 - São Paulo, SP - E-mail: delcicero@incor. usp.br 